\title{
The effect of pregnancy and lactation on food intake, gastrointestinal anatomy and the absorptive capacity of the small intestine in the albino rat
}

\author{
BY A. W. CRIPPS* AND V. J. WILLIAMS \\ Department of Physiology, University of New England, \\ Armidale, NSW 2351, Australia \\ (Received 1o December 1973-Accepted 22 fuly 1974)
}

\begin{abstract}
I. Food consumption, live weight, anatomical measurements on the gut organs and the absorptive capacity of the small intestine for L-leucine and $\mathrm{D}(+)$-glucose were made on virgin (control), pregnant and lactating albino rats.

2. Food intake increased by approximately $60 \%$ during pregnancy and a further $250 \%$ during lactation.

3. Pregnancy did not markedly influence the gross anatomy of the gastrointestinal tract. There was evidence for increased villus height and percentage water in the small intestine and for increased length of the colon during pregnancy.

4. During lactation, the alimentary canal progressively increased in weight and size. It partially regressed following weaning.

5. All anatomical measurements, except the length of the small intestine, completely regressed to control values within $20 \mathrm{~d}$ of weaning. The increased intestinal length had not completely regressed by day 30 post-weaning.

6. No significant change was observed in absolute absorption of glucose or leucine during pregnancy.

7. Absolute absorption of leucine and of glucose was increased during lactation. Greatest absorption occurred on the roth day of lactation.

8. Results for absorption of leucine and glucose per unit length indicated that the ability of the mucosal cells to absorb or the number of absorptive cells $/ \mathrm{mm}$ had changed during lactation and the post-lactation periods.
\end{abstract}

Cole \& Hart ( $\left.193^{8}\right)$ observed that food intake increased $40-50 \%$ during pregnancy in the rat. In the lactating rat, food consumption is 2-3 times greater than that of non-lactating, non-pregnant animals (Anderson \& Turner, 1963; Fell, Smith \& Campbell, 1963). This increased consumption was found to return to pre-copulation levels within $9 \mathrm{~d}$ of weaning (Anderson \& Turner, 1963 ).

During lactation, the rat alimentary canal increases in weight, length and nitrogen content (Poo, Lew \& Addis, I939; Boyne, Chalmers \& Cuthbertson, I953; Souders \& Morgan, 1957; Fell et al. 1963; Campbell \& Fell, 1964).

In the late stages of pregnancy and during lactation, hypertrophy of all layers of the small intestinal wall has been reported in rats (Fell et al. 1963; Boyne, Fell \& Robb, I966). Boyne et al. (I966) also reported an increase in intestinal mucosal surface area during lactation. This observation correlates well with the report of Cairnie \& Bentley (1967) that there is extensive hyperplasia of the small intestinal epithelium and a decreased cell transit time. The subject has been extensively reviewed by Fell (1972).

There are a number of reports demonstrating hormonal modification of intestinal

* Present address: Department of Veterinary Medicine, University of Sydney, Sydney, NSW 2006 Australia. 
Table I. Mean live weights ( $g$ ) and numbers of albino rats used in each experimental group

\begin{tabular}{|c|c|c|c|c|c|c|}
\hline \multirow[b]{3}{*}{ Experimental group } & \multicolumn{3}{|c|}{ Anatomy expts } & \multicolumn{3}{|c|}{ Absorption expts } \\
\hline & \multirow{2}{*}{$\begin{array}{c}\text { No. of } \\
\text { animals }\end{array}$} & \multicolumn{2}{|c|}{ Live weight } & \multirow{2}{*}{$\begin{array}{l}\text { No. of } \\
\text { animals }\end{array}$} & \multicolumn{2}{|c|}{ Live weight } \\
\hline & & Mean & $\mathrm{SE}$ & & Mean & SE \\
\hline Control (virgin) & I3 & $240 \cdot 3$ & $7 \cdot 0$ & 9 & $244: 9$ & $8 \cdot 8$ \\
\hline Mid-pregnancy (12-I5 d) & 6 & $240 \cdot 2$ & $6 \cdot I$ & 6 & $240 \cdot 2$ & $6 \cdot 1$ \\
\hline Parturition & 7 & $242 \cdot 6$ & $9 \cdot 8$ & 6 & $239^{\circ} 7$ & II $\cdot I$ \\
\hline $\begin{array}{l}\text { Lactation } \\
\text { Day ro } \\
\text { Day 2I }\end{array}$ & $\begin{array}{l}8 \\
8\end{array}$ & $\begin{array}{l}250 \cdot 3 \\
245 \cdot I\end{array}$ & $\begin{array}{r}18 \cdot 9 \\
8 \cdot 3\end{array}$ & $\begin{array}{l}5 \\
6\end{array}$ & $\begin{array}{l}26 I \cdot I \\
243^{\circ} 9\end{array}$ & $\begin{array}{l}29 \cdot 3 \\
10.8\end{array}$ \\
\hline $\begin{array}{l}\text { Post-weaning } \\
\text { Day Io } \\
\text { Day 20 } \\
\text { Day 3o }\end{array}$ & $\begin{array}{r}14 \\
5 \\
5\end{array}$ & $\begin{array}{l}248 \cdot 1 \\
240 \cdot 7 \\
257 \cdot 1\end{array}$ & $\begin{array}{l}6 \cdot 9 \\
9 \cdot 9 \\
2 \cdot 7\end{array}$ & $\begin{array}{l}8 \\
5 \\
5\end{array}$ & $\begin{array}{l}247 \cdot 9 \\
240 \cdot 7 \\
257^{\prime} 1\end{array}$ & $\begin{array}{l}9 \cdot 4 \\
9 \cdot 9 \\
2 \cdot 7\end{array}$ \\
\hline
\end{tabular}

absorption (Levin \& Smyth, 1963; Semen, 1968; Levin, 1969), although little is known about the effect of pregnancy and lactation on this function. In vitro studies have been made by Larralde \& Fernandez-Otero (1968) and Dugas, Hazelwood \& Lawrence (1970) and in vivo experiments by Larralde, Fernandez-Otero \& Gonzalez (1966), Pénzes \& Simon (1968), Craft (1970) and Musacchia \& Hartner (1970). The results are conflicting. Further, except for the work of Pénzes \& Simon (1968), it is not possible to determine the absorptive capacity of the whole small intestine from the results presented.

In view of this confusion the following study was undertaken to further evaluate the effects of pregnancy and lactation in the rat on anatomical changes in the whole alimentary tract and on the absorptive capacity of the small intestine for L-leucine and $\mathrm{D}(+)$-glucose, using a whole-intestine perfusion technique.

\section{MATERIALS AND METHODS}

\section{Animals}

Adult virgin, pregnant and lactating Sprague-Dawley female rats were used, and the presence of a vaginal plug was taken to indicate the start of pregnancy. The animals were housed individually in wire mesh cages and wood-wool bedding was placed in the cages of the pregnant animals on the 18 th day of pregnancy. The litters were standardized to eight pups each on day 3 post-partum. The pups were weaned at day $2 x$ post-partum. Experimental groups, mean live weights and the number of animals per group are given in Table $\mathbf{r}$.

\section{Diet}

Food cubes were supplied by Fielder's Pty Ltd, Tamworth, NSW, Australia. They contained $200 \mathrm{~g}$ crude protein and $75 \mathrm{~g}$ crude fat $/ \mathrm{kg}$. Water was provided ad lib. 


\section{Measurement of food consumption and live weights}

The control group consisted of five animals of $224 \pm \mathrm{I} 4 \mathrm{~g}$ live weight (mean $\pm \mathrm{SE}$ ), and the experimental group consisted of four animals of $196 \pm 5 \mathrm{~g}$ live weight before pregnancy. Each animal was weighed between 07.00 and 09.00 hours every 3 rd day.

Plastic sheeting was placed underneath the food bin to collect spillage. Each animal received $100-200 \mathrm{~g}$ food $/ 3 \mathrm{~d}$ : residual food was weighed every $3 \mathrm{~d}$ and consumption calculated by difference.

Mesh dividers were placed in the cages in an attempt to stop the pups gaining access to solid food. At day 18 post-partum one pup was selected at random from each litter and autopsied for intake of solid material. This procedure was repeated at weaning.

\section{Anatomical studies}

The following groups were examined: virgin controls; pregnant $12-15 \mathrm{~d}$ ('midpregnancy'); parturition; lactation days 10 and $2 \mathrm{I}$; post-weaning days ro, 20 and 30 . Mean live weight and number of animals/group are given in Table $r$. The 'parturition' group consisted of dams from which the pups were removed at birth, i.e. no suckling was permitted.

Each animal was fasted for $24 \mathrm{~h}$ prior to slaughter and at the same time the young were removed from post-partum lactating animals. The animals were anaesthetized with sodium pentobarbitone ( $50 \mathrm{mg} / \mathrm{kg}$ live weight, intraperitoneally), bled to death, eviscerated and the omentum, mesentery and fat were removed from the viscera.

The length of the small intestine (from pylorus to caecum) and colon (from caecum to rectum) was immediately measured by holding it vertically against a metre rule. Sections ( $5 \mathrm{~mm}$ long) of intestine, $60 \mathrm{~mm}$ distal to the pylorus and $60 \mathrm{~mm}$ proximal to the ileo-caecal valve, were removed, pinned to tared polystyrene bases, weighed and immersed in 10\% formol-saline fixative for histological studies.

The remainder of the small intestine, stomach, caecum and colon was treated separately. Each of these sections was cut open, washed in saline, gently blotted and weighed in a tared container to give the total wet weight. The wet weight of the small intestine was corrected to include the portions used for histological examination. Dry weights were determined after drying at $70^{\circ}$ for $48 \mathrm{~h}$.

After fixation, tissues selected for histological examination were processed in the normal way for the preparation of paraffin-wax sections. Serial longitudinal sections were cut and four subsamples (of approximately ten sections) were mounted on glass slides and stained by haematoxylin and eosin. Measurements were made of the villus heights and of the thickness of the circular and longitudinal muscle layers using a calibrated micrometer eyepiece.

\section{Measurement of absorption from the small intestine}

Surgery. Each animal was anaesthetized with a fresh solution of sodium pentobarbitone (British Drug Houses, Poole, England; $20 \mathrm{~g} / \mathrm{l}$ ) in distilled water. An initial dose of $50 \mathrm{mg} / \mathrm{kg}$ live weight was injected intraperitoneally and the animal laid on a 
Table 2. Constituents of phosphate buffer and test solution infused into albino rat intestines, and of phosphate-borate buffer for amino-nitrogen determination

Solution

Phosphate buffer

Test solution

Phosphate-borate buffer
Composition $(\mathrm{g} / \mathrm{l})$

$\mathrm{NaH}_{2} \mathrm{PO}_{4} \cdot 2 \mathrm{H}_{2} \mathrm{O}, 6 \cdot 52$

$\mathrm{Na}_{2} \mathrm{HPO}_{4}$. $\mathrm{r}_{2} \mathrm{H}_{2} \mathrm{O}, 8 \cdot 9 \mathrm{I}$

$\mathrm{NaCl}, 5^{\circ} \mathrm{O}_{3}$

Phosphate buffer (as above)

L-leucine, $I \cdot 3 \mathrm{I}$

$\mathrm{D}(+)$-glucose, $\mathrm{x} \cdot 8 \mathrm{o}$

${ }^{51} \mathrm{CrEDTA}, 2 \times 10^{3}$ counts $/ \mathrm{min}$ per $\mathrm{ml}$

$\mathrm{KH}_{2} \mathrm{PO}_{4}, 13.60$

$\mathrm{Na}_{2} \mathrm{~B}_{4} \mathrm{O}_{7} . \mathrm{IOH}_{2} \mathrm{O}, \mathrm{r} 9.06$
Osmolarity

(mosmol/l)

$\mathrm{pH}$

290

$6 \cdot 5$

3 I0

$6 \cdot 5$

$8 \cdot 5$

heated table as soon as possible. It took approximately $20 \mathrm{~min}$ for surgical anaesthesia to be induced. If required, a maintenance dose of $20 \mathrm{mg} / \mathrm{kg}$ live weight was given.

After the induction of anaesthesia, the trachea was surgically exposed and cannulated, a laparotomy was performed, and a cannula was inserted into the small intestine, approximately $5 \mathrm{~mm}$ distal to the pylorus. An incision, suitable for cannulation, was then made in the intestine about $5 \mathrm{~mm}$ proximal to the ileo-caecal junction, the intestine was flushed through the pyloric cannula with aqueous $\mathrm{NaCl}(9 \mathrm{~g} / \mathrm{l})$ and the ileal cannula inserted. The caecum was carefully positioned underneath the intestine and slightly to the left side of the abdominal cavity and the laparotomy closed with Michel clips.

Perfusion procedure. The animal was laid on its left side on a heated dissection table and connected to a peristaltic pump (Fig. I). Pump tubes of $0.165 \mathrm{~mm}$ internal diameter gave flow rates of approximately $\mathrm{I} \mathrm{ml} / \mathrm{min}$. The flow rate of each tube was regularly calibrated. To ensure complete filling of the intestine a hydrostatic pressure head of $75 \mathrm{~mm}$ was established in the perfusion line between the distal cannula and the collecting vessel (Fig. I). Once connected to the pump, the intestine was flushed with a phosphate buffer (Table 2) from a syringe connected into the perfusion line. Buffer perfusion with the pump then begun. After $\mathrm{I}_{5} \mathrm{~min}$ for equilibration, a $20 \mathrm{~min}$ collection was made of the perfused buffer solution to measure the mucosal efflux of amino acids and glucose (blank perfusion). Following the blank perfusion the intestine was flushed with the test solution (Table 2) with a 15 min equilibration period. Two $20 \mathrm{~min}$ perfusions were then made, the volumes recorded, and the solutions stored at $-20^{\circ}$ until analysed. All solutions perfused were at $36^{\circ}$. After the second perfusion $2 \mathrm{ml}$ blood was taken by cardiac puncture and the animal was bled to death.

${ }^{51}$ CrEDTA (Australian Atomic Energy Commission, Lucas Heights, NSW, Australia) was used as a non-absorbable marker in the test solutions. Hence, the volume of solution obtained during the perfusion could be equated with its equivalent in perfusion fluid from the concentration of radioactivity in the two solutions and the volume of outflow.

Determination of radioactivity. The activity of ${ }^{51} \mathrm{CrEDTA}$ was counted for $5 \mathrm{~min}$ or more, to at least 10000 counts greater than the background level, in a well-type 


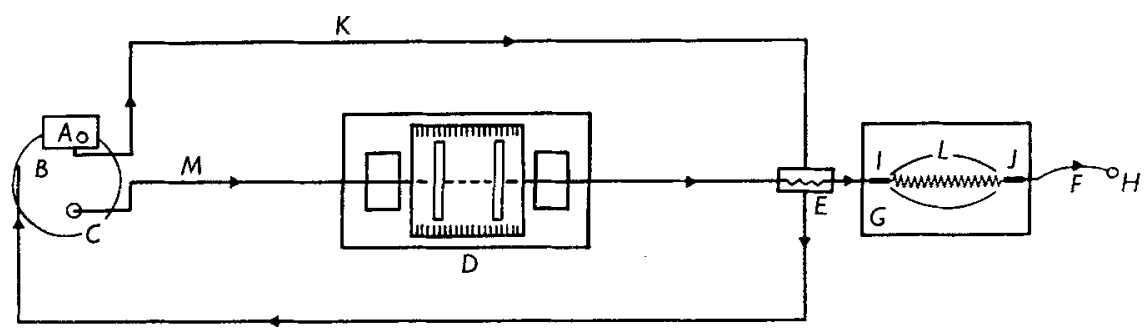

Fig. I. The apparatus used to perfuse the small intestine of albino rats. $A$, immersiontemperature regulator and constant-temperature liquid circulator; $B$, water bath; $C$, perfusionfluid container; $D$, peristaltic pump; $E$, water-jacketed coil; $F$, hydrostatic pressure head; $G$, heated dissection table; $H$, graduated collecting vessel; $I$, pyloric cannula; $\mathscr{F}$, ileal cannula; $K$, tubing from bath to water jacket of coil; $L$, experimental animal; $M$, infusion line.

counter with a $50 \mathrm{~mm}$ thallium-activated sodium iodide crystal connected to a Packard Model 3002 spectrometer (Packard Instrument Co. Inc., Downers Grove, Illinois, USA).

Chemical determinations. Blood samples were deproteinized by Haden's modification of the Folin-Wu technique (Hawk, Oser \& Summerson, r956).

Glucose concentrations in blood, test solution and perfused samples were determined by the 0 -toluidine method (Dubowski, I962) (kit sets supplied by Lavco Laboratory Inc., Hallettsville, Texas, USA).

All samples for leucine determination were made up in protein precipitant as follows: $8 \mathrm{ml} 20.8 \mathrm{mM}_{-} \mathrm{H}_{2} \mathrm{SO}_{4}$, I $\mathrm{ml}$ of the sample solution to be analysed and I $\mathrm{ml} \mathrm{I}_{5} 2 \mathrm{mM}$ $\mathrm{Na}_{2} \mathrm{WO}_{4} \cdot 2 \mathrm{H}_{2} \mathrm{O}$ were mixed. Solutions containing protein were chilled for $30 \mathrm{~min}$ and then centrifuged at $9000 \mathrm{~g}$. Distilled water ( $\mathrm{I} \mathrm{ml}$ ) instead of sample solution was used as the blank. Leucine concentrations in the test solutions and perfused sample were determined by a modification of a technique described by Satake, Okuyama, Ohashi \& Shinoda (I960). Protein precipitation resulted in the sample solutions being more acidic than those of Satake et al. ( 1960$)$. Hence, $2 \mathrm{ml}$ phosphate-borate buffer (Table 2) instead of $\mathrm{I} \mathrm{ml} 0.476 \mathrm{M}-\mathrm{NaHCO}_{3}$ was added to the sample solution to be analysed. This held the $\mathrm{pH}$ constant at the optimal level for colour development. After colour development and acidification, the sample solutions were diluted to $24 \mathrm{ml}$ with distilled water.

Extinction at 640 and $340 \mathrm{~nm}$ was measured for glucose and leucine determinations respectively using a spectrophotometer (Bausch and Lomb Spectronic 20, Model 59). The coefficients of variation of the glucose and leucine determinations were $3.1 \%$ and $2.4 \%$ respectively.

\section{RESULTS}

\section{Food consumption}

Fig. 2 shows food intake expressed on a daily basis. Food consumption increased steadily throughout pregnancy, being approximately $60 \%$ greater at termination than the control value. Immediately following parturition a slight fall in food intake was observed. A rapid increase in food intake was measured from day 3 to day 18 of lactation, the peak at day i 8 being approximately $300 \%$ greater than the control 


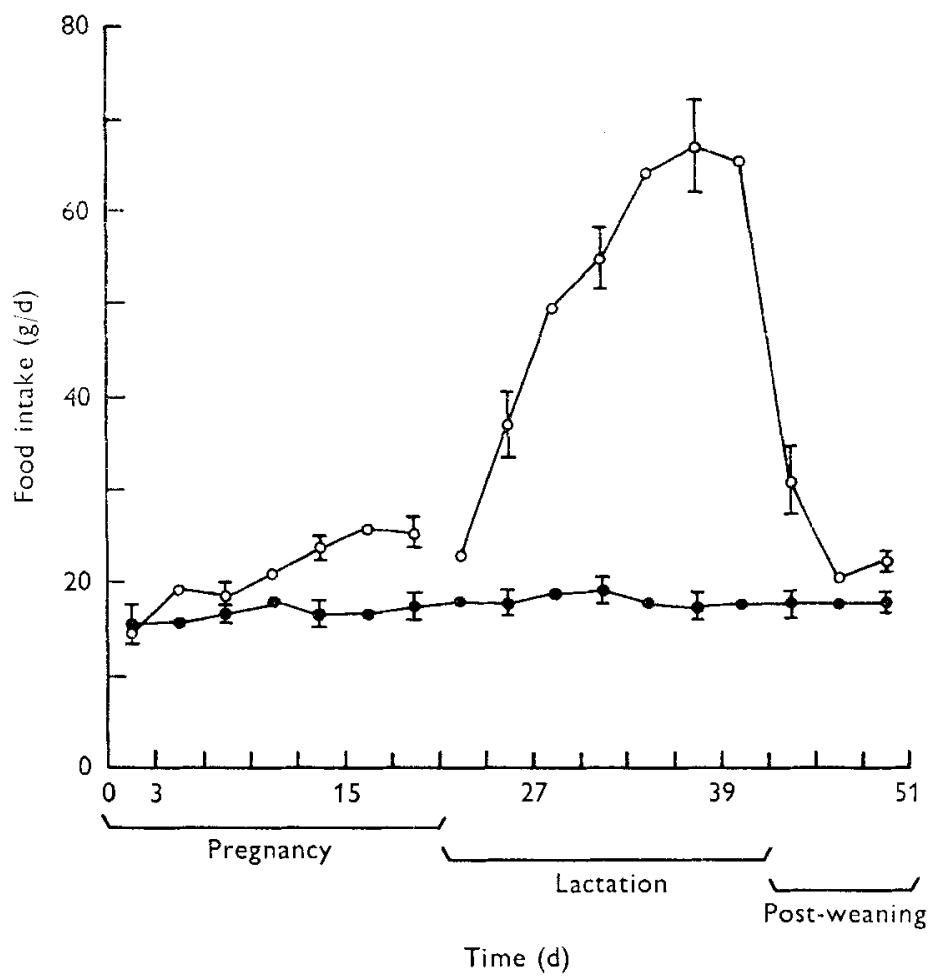

Fig. 2. Changes in daily food intake in control (virgin) albino rats and in mated albino rats during pregnancy, lactation and post-weaning; $O$, experimental group $(n=4)$; , control group $(n=5)$. Mean values with their standard errors, indicated by vertical bars, for every and mean value.

value. Food consumption fell rapidly following weaning. By day 3 post-weaning, consumption was approximately half as great as it had been $3 \mathrm{~d}$ before. By day 6 post-weaning food consumption had decreased to (mean $\pm \mathrm{SE}$ ) $20.5 \pm 2.5 \mathrm{~g} / \mathrm{d}$. This was not significantly different from the intake of the control animals.

Mesh dividers, designed to stop the pups from gaining access to solid food, were successful up to day $\mathrm{r} 8$ of lactation. After day $\mathrm{r} 8$ post-partum the young were sufficiently agile to climb the barrier. Of four pups examined at $18 \mathrm{~d}$ of age, none had eaten solid food, but of four examined at weaning all had eaten small amounts of solid material. However, it was clearly apparent that milk was still the prime dietary intake at weaning.

\section{Live weight}

The live weight of the pregnant animals had started to increase by the 3 rd day of pregnancy, the earliest recordings made (Fig. 3). There was a gradual rise, continuing to day 15 of pregnancy, after which the increase in live weight became more rapid until parturition. During lactation, live weight increased from day 3 to day 12 postpartum and remained constant to day I 8 (Fig. 3). By day 6 post-weaning the live weights of the experimental group were not significantly different from those of the virgin control group. 


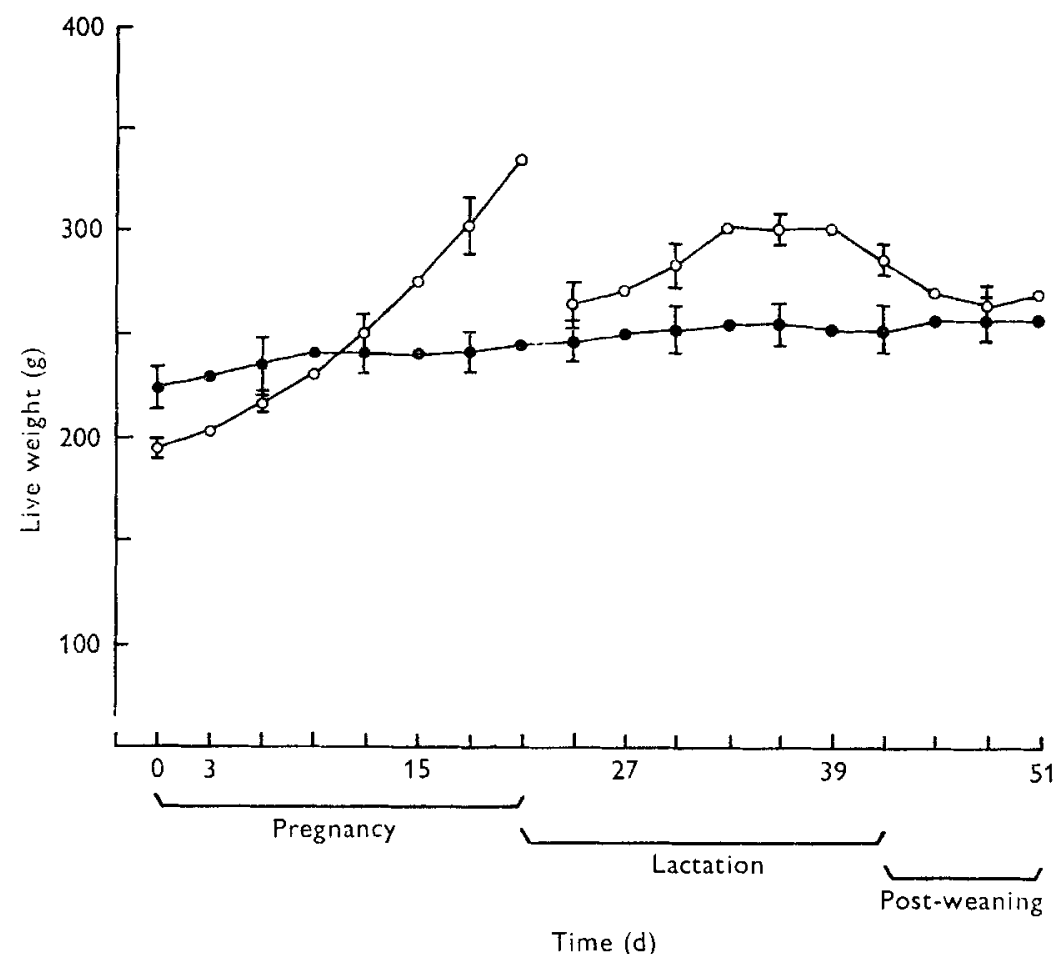

Fig. 3. Changes in live weight in control (virgin) albino rats and in mated albino rats during pregnancy, lactation and post-weaning; $O$, experimental group $(n=4)$; 0 , control group $(n=5)$. Mean values with their standard errors, indicated by vertical bars, for every and mean value.

\section{Anatomical observations}

Stomach. The stomach did not show any change in weight during pregnancy. However, during lactation there was a progressive increase in the wet and dry weights. The wet weight of the stomach on day 21 of lactation was $50 \%$ greater than control values, whilst the dry weight was $25 \%$ greater (Table 2 ). Hence, there was also a significant increase in the percentage of water during lactation (Table 4). By day 10 post-weaning the wet weight, dry weight and percentage of water were not significantly different from the control values (Tables 3,4 ).

Small intestine. During pregnancy no change was recorded in the dry weight or length of the intestine. However, significant increases in the wet weight and percentage of water were observed by the time of parturition ('Tables 3,4 ).

The villus heights in the duodenal region were significantly greater than the control values in the mid-pregnant group. This trend was further evident at parturition, but the large variation prevented any significant result (Table 5).

During lactation intestinal length increased significantly, and at day $2 \mathrm{I}$ of lactation was $21 \%$ greater than that of the controls (Table 4). Paralleling this increase in length, the wet and dry weights of the intestine also increased significantly. By day ro post-weaning the dry weight of the intestine was not significantly different from 


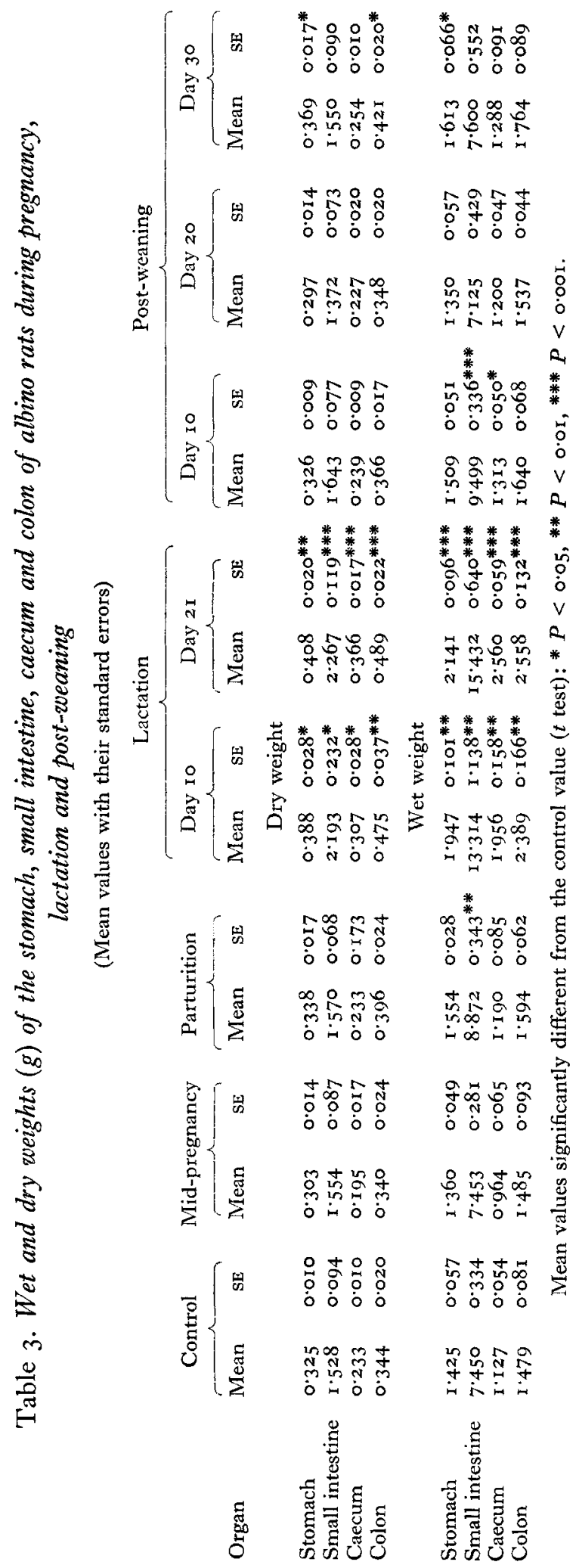




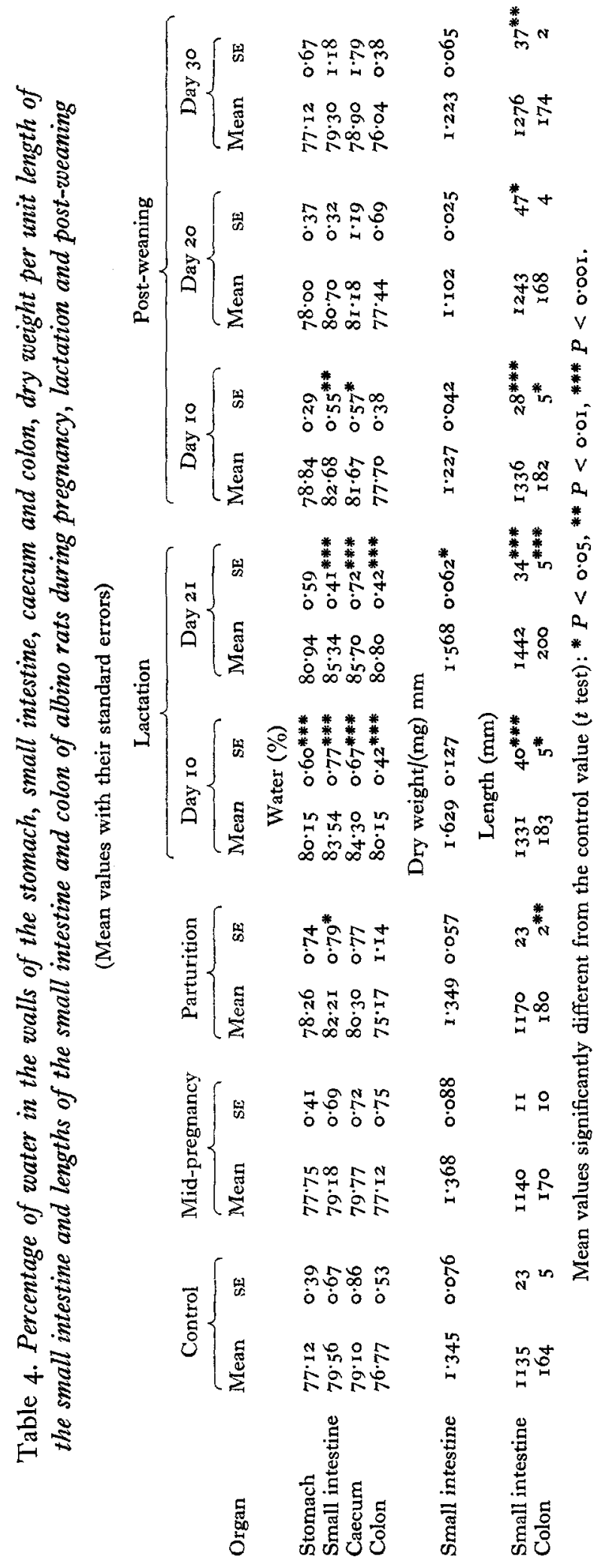


that of the controls, whilst the wet weight, and hence the percentage of water, did not regress to the control level until day 20 post-weaning (Tables 3,4 ). When the dry weight per unit length was calculated (Table 4), the proportional increase was less than for total dry weight (Table 3), indicating that the increase in weight of the intestine was caused partially by an increase in length. At days 20 and 30 post-weaning the dry weight per unit length tended to fall below the control values, although this lower value was not significantly different from the control value (Table 4 ). By day 30 postweaning the intestine was still significantly longer than that of the controls (Table 4 ).

There was an increase in villus height by day 10 of lactation at both the duodenal and ileal ends of the intestine. The villus heights in the duodenum and ileum were both approximately $55 \%$ greater at day no of lactation, compared with the control values. Villus heights tended to be greatest at day ro of lactation (Table 5). At day io and day $2 \mathrm{I}$ of lactation both muscle layers had increased in thickness by approximately $70 \%$ compared with the control value but there was no significant change in muscle thickness between day Io and day 2 I of lactation. By day io post-weaning the villus heights and muscular thicknesses were not significantly different from the control values (Table 5 ). However, at days 20 and 30 post-weaning there was a trend for the villus heights and muscle layer thicknesses to fall below the control values. For the duodenum section at day 30 post-weaning this fall was statistically significant (Table 5). Generally in the ileum and duodenum sections the circular muscle layer was thicker than the longitudinal layer. Villus heights and muscle layer thicknesses were greater in the duodenal area than in the ileal area (Table 5).

Caecum. No change in the weight or percentage of water was observed in the caecum during pregnancy (Tables 3,4 ). However, there was a significant increase in the wet and dry weights of the caecum during lactation (Table 3 ). By day 2 I of lactation the wet and dry caecum weights had increased by $127 \%$ and $57 \%$ respectively above the values for the control animals. A significant increase in the percentage of water was also observed during lactation (Table 4 ).

Colon. The length of the colon was significantly greater at parturition than control values. By day $2 \mathrm{I}$ of lactation the length was $22 \%$ greater than that of the controls, but, in contrast to the small intestine, it was not significantly different from that of the virgin controls by day 20 post-weaning (Table 4 ). During pregnancy there was no change in the weight of the colon. However, significant increases in the wet and dry weights and percentage of water were observed during lactation. At day ro post-weaning the percentage of water and wet and dry weights of the colon were not significantly different from those of the control animals (Tables 3,4 ).

\section{Absorption from the small intestine}

Absolute leucine absorption from the small intestine had increased, but not significantly, by the end of pregnancy. By day ro of lactation it was $42 \%$ greater than that in the control animals, but by day $2 \mathrm{I}$ of lactation it was only $22 \%$ greater. By day ro post-weaning absorption was still I $4 \%$ greater than that of the controls, but by day 20 post-weaning it was not significantly different from the control values (Table 6).

During pregnancy there was a tendency for absorption $/ \mathrm{mm}$ length to increase, but 


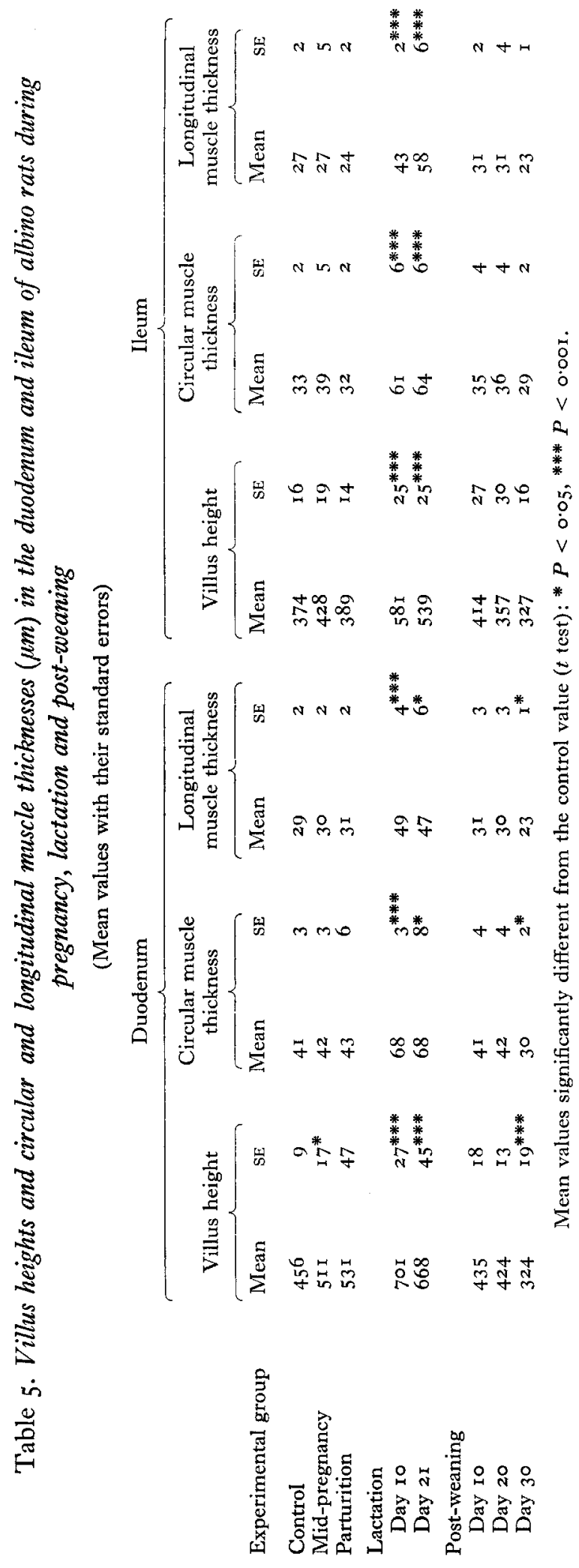




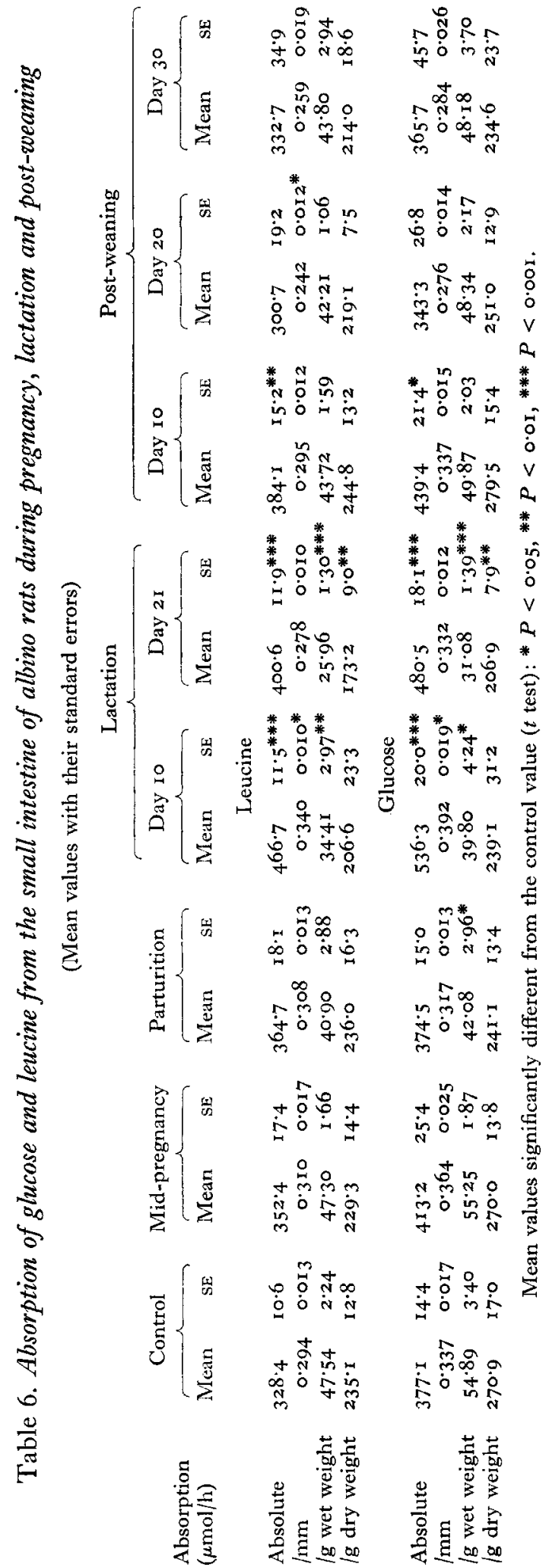


this was not significantly different from the control value. A I2\% increase was observed by day 10 of lactation, but by day $2 \mathrm{r}$ of lactation this had fallen to a value similar to that observed for the control animals, that is, the increased absorption/mm length on day ro of lactation was not sustained for the last i I d of lactation. By day 20 post-weaning, leucine absorption/mm length had fallen further to only $82 \%$ of that observed for the control animals. At day 30 post-weaning, absorption $/ \mathrm{mm}$ length was still lower than, although not significantly different from, the control values (Table 6).

There was a non-significant tendency for leucine absorption/g wet weight to decrease by the end of pregnancy compared with the control values. The values for days ro and $2 \mathrm{I}$ of lactation were significantly lower than the control values. By day $2 \mathrm{I}$ of lactation, absorption/g wet weight was only $54 \%$ of that observed in controls and animals at mid-pregnancy. Absorption of leucine, when expressed per $g$ dry weight also fell during lactation. By day ro post-weaning absorption/g dry weight and absorption/g wet weight were not significantly different from the control values (Table 6).

Absorption of glucose during pregnancy and lactation showed very similar trends to those of leucine (Table 6). In the day ro groups during lactation and post-weaning, blood glucose concentrations were significantly greater than the glucose concentration of the perfused fluid. In the remaining groups, the same trend was evident, although the differences were not statistically significant. Hence, it is apparent that part of the glucose absorption observed was the result of active transport.

\section{DISCUSSION}

It is not possible, from the live-weight values shown in Fig. 3, to differentiate the proportion of the gain due to increased gut content from that due to body tissue changes. However, live weight stayed constant between days I 2 and 18 of lactation while the food intake was still increasing, and decreased between days I 8 and 21 of lactation while the food intake was constant. This suggests the animals were drawing on body reserves for milk synthesis in late lactation.

The $300 \%$ increase in food consumption (Fig. 2) observed by day 18 of lactation is consistent with the results of other workers (Anderson \& Turner, I963; Fell et al. 1963). The rapid decline in food intake after weaning was similar to that reported by Anderson \& Turner ( 1963 ).

Our results are not consistent with those of Peters, Krijnen \& Boyd (1967) and Craft ( $197^{\circ}$ ) for the effects of pregnancy on alimentary tract anatomy, and it is possible that this is associated with the compositions of the diets used.

The observed anatomical changes in the gastrointestinal tract during lactation and post-weaning correspond well with the work of Fell et al. (1963), Campbell \& Fell (1964) and Boyne et al. (1966). However, two differences were noted. First, we found extensive enlargement of the colon, and secondly, the villus heights in the ileum were found to increase in the same proportion as those in the duodenum.

The increased wet and dry weights of all organs of the gastrointestinal tract and the increased length of the colon and small intestine during lactation indicated that vast changes occurred at the cellular level. Fell et al. (1963) observed hypertrophy of the 
parietal cells in the stomach and of the caecum epithelial cells, while Cairnie $\&$ Bentley (1967) showed that there is extensive hyperplasia of the mucosa of the small intestine.

Whether hypertrophy or hyperplasia or both occur in the small intestinal musculature during lactation cannot be determined from our results. Values for the DNA: protein ratio of the muscle layers would help to define this situation.

The over-all decrease in the thickness of the wall of the small intestine after weaning when compared with that of the control animals explains why, although the intestinal length in the post-weaning period was constant, the weights were not significantly different from those of the controls.

Fell et al. (1963) have suggested three possible causes of the hypertrophy of the alimentary canal during lactation.

The first was that the changes are due to 'work hypertrophy'. This is supported by the parallelism between hypertrophy of the alimentary canal and the increased food consumption throughout lactation. However, the results of experiments reported by Addis (r932) and Dowling, Riecken, Laws \& Booth (1967) suggest that the increase in dry-matter intake resulting from the inclusion of indigestible constituents in the food of the rat does not have an important effect on the weight of the small intestine but induces a significant increase in size and weight of the stomach, colon and particularly the caecum. Thus, it is unlikely that work load is the factor causing the increase in size of the small intestine during lactation, but it could explain at least some of the development of the other gut organs.

The second was that hormonal changes are responsible. In rats, hyperthyroidism causes an increase in intestinal weight (Levin \& Smyth, 1963) and Grosvenor \& Turner $\left(195^{8}\right)$ have shown that thyroxine secretion is substantially increased during lactation. On the other hand, prolactin has not been demonstrated to cause increased appetite in rats (Cotes \& Cross, 1954) nor intestinal hypertrophy in mice (Campbell \& Fell, 1964).

The third hypothesis was that alimentary enlargement could be a functional adaptation of the mucosa to the increased bodily demands of lactation, independent of the level of food intake. This has been given little consideration in the literature. As the digestibility of food does not decline greatly during lactation (Campbell \& Fell, 1964) although there is a large increase in food intake, closer examination of this hypothesis is required.

It is apparent that enlargement of the stomach, caecum and colon may be a partial consequence of the 'work hypertrophy' due to the increased food consumption associated with lactation. However, for the small intestine this hypothesis is not convincing and confounding hormonal and nutritional factors may be involved. Weser (1971) has suggested that mucosal hypertrophy of the small intestine is associated only with the greater supply of digestible nutrients to the mucosa.

The major problem associated with the perfusion technique was the interruption of the flow of perfusate through the intestine due to localized intestinal contractions and the presence of mucus. However, although these techniques have various limitations (Soergal, 1971), they are believed to be an improvement on the closed-loop method described by Matthews, Craft, Geddes, Wise \& Hyde (1968). 
Reports on absorptive function of the small intestine in pregnancy and lactation are based on a variety of experimental techniques. Craft (1970), Dugas et al. (1970) and Musacchia \& Hartner (1970) used either an in vitro technique or short closed loops in vivo. It is not possible to extrapolate from these results to obtain a measure of the absorptive capacity of the whole intestine. Consequently no valid comparison can be made with the results obtained by the infusion of the whole small intestine.

The results of the present work suggested that absolute absorption of leucine and glucose is not significantly enhanced during pregnancy. This relates well to relatively slight anatomical changes in the small intestine. Thus the rat can cope with digestion and absorption of a $60 \%$ increase in food intake with little adjustment of the gut.

Pénzes \& Simon (1968) used a static system involving the whole small intestine and showed that the absorption of DL-methionine increased during lactation but had fallen to unmated control values by day $2 \mathrm{r}$. The results presented here show that L-leucine absorption was $22 \%$ greater on day 21 of lactation than in virgin controls, having fallen from a value $42 \%$ greater on day ro. It is possible that the difference in behaviour of the two amino acids may not be physiological but the result of the different techniques employed, or it may be that the time course for the fall in absorptive capacity of the small intestine in the latter half of pregnancy is not the same for all amino acids.

When the results for lactation were expressed as absorption/unit weight of intestine, rather than in absolute values, a marked fall was observed compared with control animals for both leucine and glucose. Interpretation of results expressed on a weight basis should be treated with caution because of the vast changes in intestinal morphology which occur during lactation. It is possible that, during lactation, intestinal weight may not bear a direct relation to mucosal surface area due to a greater increase in the weight of muscle layers per unit length of intestine as compared with mucosa.

Expression of the results per unit length requires special emphasis. First, the significant increase in absorption $/ \mathrm{mm}$ length by mid-lactation indicates that the absorptive ability $/ \mathrm{mm}$ length of intestine was enhanced. Secondly, on day 21 of lactation, absorption/mm length was not significantly different from that of the controls. In view of the fact that at this time intestinal length was maximal and absolute absorption was significantly lower than it had been on day ro of lactation, the absorptive capacity of the intestine was reduced over the last I I $\mathrm{d}$ of lactation.

It would be of great interest to know whether the absorption of some amino acids/ unit length of small intestine can fall to values below that of virgin controls during late lactation while food intake is still maximal. The results of Pénzes \& Simon (Ig68) suggest that this is possible for methionine.

Finally, at day 20 post-weaning, absorption/mm length was substantially below that of virgin control animals. While absolute absorption had returned to control values by this stage, intestinal length had not. Hence, it is apparent that absorptive ability/mm length was reduced, whilst absolute absorptive capacity was equal to that of the virgin controls. This suggests that during the post-lactation regression phase the mucosal cells associated with absorption regress faster than the structural 
tissues of the intestine. It is possible that the increased intestinal length resulting from first lactation does not completely regress.

The increase of $\mathrm{D}(+)$-glucose and $\mathrm{L}$-leucine absorption during lactation meets the generally higher demands of the lactating animal for nutrients. In the lactating simple-stomached animal, glucose is the principal precursor for lactose and glycerol in milk. Leucine has not been demonstrated to be an essential amino acid for lactation in the simple-stomached animal (McDonald, Edwards \& Greenhalgh, I971).

Cotes \& Cross (1954) have shown that the increase in food intake in the rat during lactation is primarily the result of suckling and therefore presumably is due to nerve impulses from receptors in the teat areas stimulating the hypothalamic appetite centre. The increase in ability of the small intestine to absorb nutrients could be secondary to the increase in appetite. However, there is no evidence that it is not a response to a changed hormonal status of the animal. In fact both suckling and hormonal factors may be implicated.

\section{REFERENCES}

Addis, T. (1932). Am. F. Physiol. 99, 417.

Anderson, R. R. \& Turner, C. W. (I963). Proc. Soc. exp. Biol. Med. II3, 334.

Boyne, A. W., Chalmers, M. I. \& Cuthbertson, D. P. (1953). Hoppe-Seyler's Z. physiol. Chem. 295, 424.

Boyne, R., Fell, B. F. \& Robb, I, (1 966). F. Physiol., Lond. 183, 570.

Cairnie, A. B. \& Bentley, R. E. (1967). Expl Cell Res. 46, 428.

Campbell, R. M. \& Fell, B. F. (1964). F. Physiol., Lond. I71, 90.

Cole, H. H. \& Hart, G. H. (1938). Am. F. Physiol. 123, 589.

Cotes, P. M. \& Cross, B. A. (1954). F. Endocr. ro, 363 .

Craft, I. L. (1970). Clin. Sci. 38, 287.

Dowling, R. H., Riecken, E. O., Laws, J. W. \& Booth, C. C. (1967). Clin. Sci. 32, I.

Dubowski, K. M. (1962). Clin. Chem. 8, 215.

Dugas, M. C., Hazelwood, R. L. \& Lawrence, A. L. (1970). Proc. Soc. exp. Biol. Med. 135, 127.

Fell, B. F. (1972). Wld Rev. Nutr. Diet. x4, I80.

Fell, B. F., Smith, K. A. \& Campbell, R. M. (1963). F. Path. Bact. 85, r79.

Grosvenor, C. E. \& Turner, C. W. (1958). Proc. Soc. exp. Biol. Med. 99, 517.

Hawk, P. B., Oser, B. L. \& Summerson, W. H. (1956). Practical Physiological Chemistry p. 543. London: Churchill.

Larralde, J. \& Fernandez-Otero, P. (1968). Revta esp. Fisiol. 24, 49.

Larralde, J., Fernandez-Otero, P. \& Gonzalez, M. (г 966). Nature, Lond. 209, 1356.

Levin, R. J. ( 1969$)$. F. Endocr. 45, 315.

Levin, R. J. \& Smyth, D. H. (1963). F. Physiol., Lond. 169, 755.

McDonald, P., Edwards, R. A. \& Greenhalgh, J. F. D. (1971). Animal Nutrition p. I56. Edinburgh: Oliver and Boyd.

Matthews, D. M., Craft, I. L., Geddes, D. M., Wise, I. J. \& Hyde, C. W. (I 968). Clin. Sci. 35, 41 5.

Musacchia, X. J. \& Hartner, A. M. (1970). Proc. Soc. exp. Biol. Med. 135, 307.

Pénzes, L. \& Simon, G. (1968). Fap. F. Physiol. 18, 288.

Peters, J. M., Krijnen, C. J. \& Boyd, E. M. (r967). \%. Reprod. Fert. 14, 235.

Poo, L. J., Lew, W. \& Addis, T. (1939). F. biol. Chem. 128, 69.

Satake, K., Okuyama, T., Ohashi, M. \& Shinoda, T. (1960). F. Biochem., Tokyo 47, 654.

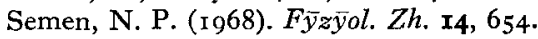

Soergal, K. H. (1971). Gastroenterology 6r, 26r.

Souders, H. J. \& Morgan, A. F. (1957). Am. F. Physiol. r9r, I.

Weser, E. (I97 I). Am. F. clin. Nutr. 24, I33. 